\title{
UM CURRÍCULO-MUSEU COM GÊNERO: experimentações para produzir (des)objetos
}

\author{
Cláudio Eduardo Resende Alves \\ Universidade Federal de Minas Gerais - UFMG, Brasil \\ Marlucy Alves Paraíso \\ Universidade Federal de Minas Gerais - UFMG, Brasil
}

\begin{abstract}
Resumo
Este artigo apresenta e problematiza um currículo-museu com gênero, destacando sua concepção, modos de operar e possibilidades no campo do aprender. A partir de interações com os chamados (des)objetos do acervo do Museu de Artes e Ofícios de Belo Horizonte/MG foi realizada uma pesquisa-experimentação de pós-doutorado em Educação. Com base nos estudos pós críticos de gênero e currículo e com contribuições da pedagogia do multiletramento, o pesquisador percorreu o museu munido de seu diário de campo e da observação participante do cotidiano de visitas docentes e discentes. Para a construção do texto, foram selecionados três (des)objetos - um carro de boi, uma bolsa bruaca, e uma panela de pedra - como elementos problematizadores na pesquisa teórica e empírica. Os resultados evidenciam que um currículo-museu com gênero oportuniza encontros potentes com (des)objetos em museus, gerando inquietações, desestabilizações e deslocamentos no exercício do aprender sobre as relações de gênero. O estudo aponta a relevância de uma abordagem curricular aberta à cultura e às diferentes leituras de mundo.
\end{abstract}

Palavras-chave: Currículo; Gênero; Museu.

\begin{abstract}
This article presents and problematizes a curriculum-museum with gender, highlighting its conception, modes of operation and possibilities in the field of learning. Based on interactions with the so-called (dis)objects from the collection of the Museum of Arts and Crafts of Belo Horizonte/MG, a post-doctoral research and experimentation in Education was conducted. Based on the post-critical studies of gender and curriculum and with contributions from the pedagogy of multileteering, the researcher traveled through the museum with his field diary and participant observation of daily visits of teachers and students. For the construction of the text, three (de)objects were selected - an ox cart, a bruise bag, and a stone pot - as problematizing elements in theoretical and empirical research. The results show that a curriculum-museum with gender enables powerful encounters with (dis)objects in museums, generating restlessness, destabilizations and displacements in the exercise of learning about gender relations. The study points out the relevance of a curricular approach open to culture and different world readings.
\end{abstract}

Keywords: Curriculum; Gender; Museum. 


\section{Introdução}

A expressão reta não sonha. Não use o traço acostumado. Arte não tem pensa: $\mathrm{O}$ olho vê, a lembrança revê e a imaginação transvê. É preciso transver o mundo [...] Os artistas desformam. É preciso desformar o mundo. Tirar da natureza as naturalidades (BARROS, 2014, p.102)

A astúcia poética de Manoel de Barros provoca e nos inspira a fazer um convite para analisar resultados de uma pesquisa que investigou possibilidades de discussões de gênero no currículo de museus. O convite é: entre em um museu de corpo inteiro, com os sentidos aguçados e o desejo desperto! Transveja o museu! Olhe por outro ângulo! Insista! Volte a olhar! Lembre o esquecido e imagine o inimaginável! Rompa com as formas e normalidades que aprisionam objetos de um museu numa leitura reta, num traço acostumado! Conclame a arte! Desformate objetos e, por consequência, produza (des)objetos. O uso do parenteses na palavra é uma escolha léxica autoral para destacar e incluir a dimensão do próprio objeto na concepção poética do (des)objeto.

Visitar um museu é entrar em contato com diferentes (des)objetos. Podemos dizer que (des)objetos residem em um "espaço indefinível e misterioso entre as palavras e os objetos" (PAQUET, 2006, p. 68), entre o nome e a coisa (FOUCAULT, 1988). (Des)objetos se manifestam como simulacros que escorregam entre diferentes significados, produzindo modos de subjetivação, ou seja, modos de produção de formas de existência no mundo que operam por meio de "práticas discursivas e práticas de poder que testemunham pela descontinuidade de suas formas históricas" (FOUCAULT, 1984, p. 23). A expressão de nossa relação com as coisas apresenta subjetividades demarcadas por dispositivos historicamente construídos, nessa direção o museu se configura como um locus privilegiado por nele habitarem artefatos culturais e históricos que produzem subjetividades. No museu, a medida em que dispositivos históricos se transformam e novas práticas de subjetivação se engendram, (des)objetos podem provocar a desestabilização e a movimentação entre a metafísica das memórias e afetos que um objeto pode evocar e a materialidade verificável desse mesmo objeto como peso, tamanho, volume, cor e técnica.

Para se conceber um currículo-museu com gênero é preciso estar aberto ao estranhamento com (des)objetos, desestabilizar o pensamento e deslocar a forma de olhar para o mundo. O currículo, entendido como um artefato cultural permeável à diferença (PARAÍSO, 2010), pode valorizar a multiplicidade e a transgressão, atuar "na zona do indeterminado e da interrogação" (PARAÍSO, 2010, p. 602) e ajudar a estranhar o museu. Gênero aqui é tomado como uma categoria analítica relacional, discursiva e performativa (BUTLER, 2018) que impacta o aprender, mas também como uma linguagem que produz nomeações e taxinomias classificatórias para coisas, corpos e sujeitos a partir de uma norma, evidenciando incongruências (ALVES, 2020). Pensar o museu no âmbito das relações de gênero é problematizar as representações patrimoniais, os acervos com seus (des)objetos, a curadoria, os atores e as atrizes que partilham daquele espaço, buscando outras memórias, outros arranjos e outros marcadores sociais. 
Este artigo apresenta resultados de uma pesquisa de Pós-Doutorado em Educação na Universidade Federal de Minas Gerais, realizada no biênio 2019/2020, que teve como cenário para experimentações o Museu de Artes e Ofícios de Belo Horizonte/MG. Tal escolha se deu em razão de que esse museu faz parte do projeto institucional "Percurso Museológico História de Mulheres: vozes e silêncios" (ALVES e SOUZA, 2017) da Secretaria Municipal de Educação de Belo Horizonte que, desde 2013, trabalha com a discussão sobre gênero no museu.

Na pesquisa-experimentação que subsidia esse artigo, o investigador munido pelo desejo de articular currículo, gênero e museu selecionou e problematizou três (des)objetos do Museu de Artes e Ofícios no sentido de criar possibilidades para a experimentação de um currículomuseu com gênero, são eles: 1 . Um carro de boi do Ofício dos Transportes; 2. Uma bolsa bruaca usada no Ofício do Comércio; e 3. Uma panela de pedra do Ofício da Conservação e Transformação dos Alimentos. O argumento aqui desenvolvido é de que um currículo-museu com gênero oportuniza encontros com (des)objetos em espaços museais que podem produzir inquietações, desconfortos e deslocamentos no exercício do aprender sobre as relações de gênero, ao mesmo tempo em que possibilita a abertura às composições com arte, afetando e sendo afetado.

Para desenvolver esse argumento, a partir daqui, o artigo está dividido em mais quatro partes que, para usar uma palavra cara aos museus, chamamos de acervos. No $\mathbf{1}^{\mathbf{0}}$ acervo: Artistas, encontros e (des)objetos, discutimos a concepção e as imbricações de (des)objetos a partir de obras de quatro artistas: Manoel de Barros, René Magritte, Franz Kafka e Tarsila do Amaral. No $\mathbf{2}^{\mathbf{0}}$ acervo: Letramento museal, apresentamos diálogos com o campo do multiletramento, em especial, do letramento museal e da Museologia Social como estratégias metodológicas de intervenção com (des)objetos. No $3^{\mathbf{o}}$ acervo: Composições com (des)objetos no museu, a partir dos relatos registrados no diário de campo da pesquisa problematizamos composições com três (des)objetos do museu - carro de boi, bolsa bruaca e panela de pedra - sobre as relações de gênero, nem sempre perceptíveis, que os habitam. Por fim, no $4^{\mathbf{0}}$ acervo: Efeitos de um currículo-museu, sistematizamos o caminho percorrido na pesquisa-experimentação e sinalizamos desdobramentos na ampliação da concepção de um currículo-museu com gênero.

\section{Primeiro acervo: Artistas, encontros e (des)objetos}

O primeiro acervo deste artigo ensaia uma definição para (des)objetos no museu por meio do diálogo com quatro artistas de diferentes épocas, países e estilos. A escolha dos/das artistas se deu pela potência atemporal de suas obras na reflexão sobre vida, diferença e estranhamento e também por fazerem da arte um elemento propulsor de escapes da normalidade. Apesar de não terem gênero como elemento central de suas obras, eles/as buscaram através da arte desformatar o ordinário e transver do mundo, o que acaba aproximando-os/as de (des)objetos de um museu. Os diálogos possíveis dos/as artistas convidados/as com (des)objetos operam uma espécie de atentado de algum tipo de arte que 
interpela e, felizmente, engana. São obras que escorrem pelos dedos e que se tornam outras ao serem indagadas.

Assim, Manoel de Barros introduz à ideia de (des)objetos literários, Renê Magritte interroga sobre as interferências entre imagem e palavra na figura de seu "não-cachimbo", Franz Kafka apresenta a instigante, nômade e incapturável criatura Odradek e Tarsila do Amaral, com seu Abapuru, leva a repensar as incertezas culturais brasileiras por meio do vanguardista Movimento Artístico da Antropofagia.

O primeiro diálogo é com o artista escritor Manoel de Barros (1916-2014) que produziu e nomeou cerca de trinta e cinco (des)objetos, embora não tenha conceitualizado o (des)objetos. Para o poeta, os "mais bolinados são alicate cremoso, abridor de amanhecer, parafuso de veludo, fivela de prender silêncios e prego que farfalha" (BARROS, 2014, p.118). Tais (des)objetos trazem a possibilidade de estar "entre lugares", entre a poesia e a materialidade, entre a metafísica e o mundo físico, entre o abstrato e o concreto. Entre palavras e objetos existem muitos indizíveis que podem promover fissuras na normalidade, segundo o próprio poeta, "[eu] gostava das palavras quando elas perturbavam o sentido normal das ideias" (BARROS, 2014, p.141).

Imbuídos/as desse espírito artístico de perturbação da ordem no mundo, cabe-nos questionar: o que é um (des)objeto? Um (des)objeto está em constante desestabilização e deslocamento, produzindo uma dissolução entre as oposições rígidas conceituais, nas quais cada categoria preserva o traço da categoria oposta. (Des)objetos tem potencial disruptivo por seguirem na contramão e no avesso do regular. Eles estão sempre em movimento, por meio do qual os sentidos produzidos escorregam uns sobre os outros, se deslocam, mudando de lugar e de domínio, deslocando também as percepções de quem interage com eles. (Des)objetos são poéticos, estéticos e nômades. O nômade "não é extraterrestre nem abstrato, sem sentido; é da Terra, andante, errante, poético, politico" (PARAÍSO, 2015, p. 273), não têm fixidez e não limita territórios. Eles podem até ser temporariamente capturados no movimento e na ação, mas logo se metamorfoseiam e se libertam.

O segundo diálogo é com o artista pintor Renê Magritte (1898-1967) que propõe em suas obras a "libertação das aparências de forma provocadora e surpreendente" (PAQUET, 2006, p. 23). Uma de suas pinturas mais polêmicas e alvo de muitos estudos é intitulada "Isto não é um cachimbo" de 1928. Nela, Magritte subverte a percepção artística ao associar imagem e palavra de forma tautológica, pois ambos não são cachimbos, uma é a frase "Isto não é um cachimbo" e a outra é uma imagem que remete, apenas remete, ao objeto cachimbo. Foucault (1988) percebe o quadro de Magritte como um caligrama, ou seja, um poema visual que forma um pictograma representando um objeto real ou figura que é a imagem principal do poema. Esse poema visual aproxima letras e objeto, pois "[...] as palavras são da mesma substância que as imagens" (FOUCAULT, 1988, p.51). O "não-cachimbo" de Magritte também se aproxima de um (des)objeto ao gerar inquietações e deslocamentos a partir de um objeto supostamente ordinário - um cachimbo. Trata-se de uma espécie de traição da imagem pela palavra, especialmente numa civilização marcada pela tradição multissecular do texto escrito em detrimento da imagem. 
A definição de uma coisa se apoia na linguagem como ferramenta nominativa, porém também a linguagem não consegue capturar a coisa, uma vez que ela, como expressão discursiva, consiste num "rastreamento da realidade, sem nunca alcançá-la" (DERRIDA, 2006, p. 87). (Des)objetos são incompletos, ainda que as interações percebidas com o outro em diferentes territórios momentaneamente passem uma ideia de completude. Por serem acontecimentos, (des)objetos são plenos em momentos de escape e de desformatação. Isso ocorre, por exemplo, quando estudantes visitam um museu e provocam reflexões inusitadas acerca deles, como algum detalhe do acervo ou do prédio despercebido pela equipe do educativo do museu ou ainda quando resolvem burlar regras, deitando no chão do museu para observar (des)objetos sob outra perspectiva.

O terceiro diálogo é com o artista escritor Franz Kafka (1883-1924). Em seu romance “A preocupação de um homem de família” de 1917, Kafka apresenta o Odradek, uma criatura misteriosa que habita diferentes espaços, podendo estar tanto no forro quanto debaixo do vão da escada ou ainda nos corredores de uma casa e quando alguém tenta entrar em contato, ele guarda silêncio. Odradek impõe o tempo todo ao/à leitor/a o esforço de capturá-lo e categorizá-lo, numa tentativa permanente de encerrá-lo em um conceito fechado. A criatura Odradek desloca as possibilidades de expressão de gênero nas línguas (IZABEL, 2016), promovendo fraturas nos discursos hegemônicos, no "pensamento totalitário, que odeia os fios soltos do hibridismo [...] que odeia a inclassificabilidade" (IZABEL, 2016, p. 79). Podese dizer que o Odradek kafkaniano, com seu deslocamento constante, seus silêncios guardados, sua não fixidez e sua incompletude guarda semelhanças com (des)objetos no museu ao destacar sua característica mais valiosa, a ausência de consenso. Assim como o hibridismo linguístico do Odradek, (des)objetos podem ser enunciados no feminino, no masculino ou em ambos. Não existe um gênero pré-determinado, nem estável.

Tamanho, forma, peso, cor, técnica e outras propriedades determinam objetos, mas no momento em que se articulam organicamente com memórias, afetos e emoções aproximamse da noção de (des)objetos. Assim como no currículo-nômade, nos (des)objetos algo sempre escapa e vaza (PARAÍSO, 2010), refutando qualquer ideia de totalidade, pois deixam restos (DERRIDA, 2006) por onde passam. Por isso, é tão difícil defini-los. A emergência das qualidades de um (des)objeto está na contramão da linha reta, óbvia e insipiente. Com (des)objetos desfazem-se as essências e as identidades dos objetos, assim um currículomuseu aposta nos encontros com o inusitado para tornar-se desejante de aprender e potencializar suas práticas educativas.

O quarto e último diálogo é com a artista pintora Tarsila do Amaral (1886-1973), por meio de sua obra Abaporu de 1928 que significa "homem que come gente" na língua tupiguarani. O título da obra nos remete ao movimento da vanguarda artística modernista do início do século XX chamado Antropofágico. Como um manifesto artístico e decolonial, a Antropofagia propôs a valorização da cultura local e nacional em contrapartida ao estrangeirismo no campo da arte importado pelo Brasil. Na obra, a imagem de um corpo nu - nem de homem, nem de mulher ou, talvez, de ambos - de cabeça pequena e mãos e pés enormes repousados sobre a terra com ar pensativo incomoda pela sua incertitude e indefinição. A plasticidade do corpo the confere uma dimensão criativa, histórica e 
transformacional (FOUCAULT, 1984). As composições entre a mulher artista de vanguarda, o título da obra na língua indígena e a imagem corporal inapreensível a primeira vista do Abaporu dialogam com (des)objetos à medida que oferece mais dúvidas que respostas, mais instabilidades do que certezas e mais escapes do que achados.

Nos encontros com a arte da composição, Tadeu (2002) aponta que devemos saber cultivá-los como "aqueles que nos ajudam a nos apartar do efêmero e do contingente para experimentar um gostinho do infinito e do eterno" (TADEU, 2002, p. 56). Pensando na arte como "excitante do querer" (DELEUZE, 2018, p. 131), outros/as artistas poderiam dialogar nos encontros com (des)objetos e gênero no museu, entretanto, tivemos que fazer um recorte em função do espaço do artigo como resultado da pesquisa sobre a ampliação da abordagem curricular, o que acabou por deixar muitos/as artistas de fora dessa conversa.

Entre incertezas, perturbações e não classificações no universo da arte, um currículomuseu com gênero opera por meio de encontros com (des)objetos, encontros que envolvem emoção, centram-se na experiência, nas relações e envolvem um fazer e um sair dos lugares. Em seu nomadismo, um currículo-museu "pode ser construído por cada um/a de nós [...] que sente o desejo de mover a vida e de construir um outro mundo" (PARAÍSO, 2015, p. 277). Essa proposta de currículo ocorre à medida que acontece, no ato da interação com o (des)objetos do acervo e com o território do museu. Interação essa que é fluida e movediça, uma vez que o "nômade não tem pontos, trajetos, nem terra, embora evidentemente ele os tenha" (DELEUZE e GUATTARI, 2012, p. 56). O nomadismo nos (des)objetos de um museu fraturam os limites de seu suposto propósito abrindo espaço para a experiência inesperada e, de alguma forma, dissidente.

\section{Segundo acervo: Letramento museal}

No museu, para produzir estranhamentos nos encontros com (des)objetos, do ponto de vista pedagógico, torna-se necessário criar estratégias metodológicas de intervenção e produção de sentidos. Para tanto, uma abordagem pedagógica ampliada e direcionada ao aprender no museu pode viabilizar práticas interativas e comunicativas com (des)objetos por meio das quais seja possível problematizar as relações de gênero que os atravessam. A proposta das visitas de docentes e discentes ao museu, numa referência à Magritte com seu "não-cachimbo", é produzir uma espécie de poema visual que aproxima o objeto do acervo museal ao campo da linguagem, criando composições com gênero.

Em conversa com educadores/as do museu durante a pesquisa-intervenção, relataram que certos/as docentes quando chegam ao espaço museal querem transpor a lógica de funcionamento da escola para o museu, relacionando-se com o acervo pelo viés binário sujeito/objeto e transmissão/recepção nas práticas do aprender. Avesso a essa postura, a equipe de profissionais do setor educativo tem como prática educativa e museal a produção de ruídos problematizadores de gênero nas visitas mediadas de docentes e discentes. A partir do acervo museal, os/as visitantes são convidados/as a compor com os artefatos culturais em exposição. Para tanto, a equipe investe em momentos internos de formação, leitura e 
ampliação da percepção do museu como instituição educadora, afinal o próprio museu é produzido pelo gênero e também produtor de gênero.

Um currículo-museu caminha no sentido de produzir composições e deslocamentos com (des)objetos desformatando-os e transvendo-os com possibilidades de aprender em movimento. Destituir (des)objetos de sua suposta natureza e, com isso, produzir hibridismos linguísticos para pensar gênero, assim como a criatura Odradek de Kafka com sua errância, incompletude e nomadismo. Sendo gênero demarcado morfologicamente na língua e literalizado em objetos do museu, os encontros com (des)objetos no museu sugerem a desliteralização dos objetos, livrando-os de sua ontologia material e abrindo-se para outras experimentações com a linguagem gênero.

Nesse sentido, fomos buscar na pedagogia do multiletramento (THE NEW LONDON GROUP, 1996) uma contribuição, posto que sua concepção de educação reside no fomento de práticas pedagógicas em que estudantes se tornem criadores/as de sentidos, analistas críticos/as e na ressignificação dos discursos de gênero. A pedagogia do multiletramento pode ser entendida como a possibilidade de desenvolvimento de múltiplas linguagens, para além da tradicional leitura e escrita, capazes de se modular frente a diferentes contextos e situações culturais, nos quais concepções, críticas e percepções fluam democraticamente em uma perspectiva horizontal.

Argumentar, compreender, questionar e imaginar são práticas ou eventos de letramento (ALVES e SOUZA, 2017) que dialogam com a perspectiva do currículo-museu, pois trazem a indagação reflexiva como elemento do aprender. A permanente busca por possibilidades constitui o currículo, alimentando-o e tornando-o múltiplo. Considerar a diferença na prática do multiletramento em um currículo-museu, isto é, na multiplicidade de leituras de mundo no currículo, gera movimento, uma vez que "currículos [...] são 'realidade em potencial', que ainda não foram formados" (PARAÍSO, 2019, p. 195).

Entre os múltiplos letramentos que podem movimentar um currículo, destacamos o letramento museal (ALVES e SOUZA, 2017) na busca por saberes necessários para estabelecer relações de criação e reinvenção no aprender. Esse tipo de letramento busca compreender as funções sociais de um espaço e de seu acervo, considerando suas complexas habilidades linguísticas orientadas por interesses pessoais e fatores contextuais de aprendizagem formal ou informal (CARVALHO, 2011) que modelam as estratégias de experimentação em um museu. No currículo-museu, importa-nos questionar sobre quais concepções de gênero estão presentes nos museus e sobre como os museus inserem essa discussão em suas práticas. O letramento museal nos convida a uma leitura de mundo a partir dos espaços museais, investigando o que um museu pode dizer sobre gênero. Vivenciar o letramento museal ou promover práticas sociais de linguagem para compreensão de mundo no museu (ALVES e SOUZA, 2017) é produzir outras narrativas em outros espaços e tempos possíveis.

O campo da museologia tem utilizado metodologias interdisciplinares a fim de abranger discussões contemporâneas, como as relações de gênero no museu, sendo objeto de estudo de autores/as de diferentes campos do conhecimento como a "sociomuseologia" (MOUTINHO, 2007, p. 425), a "museologia da mulher e de gênero" (VAQUINHAS, 2014, 
p. 3) e a "museologia social e de gênero" (RECHENA, 2014, p. 169). A pesquisadora Rechena (2014) propõe três dimensões para o trabalho com gênero nos museus: 1 . O rompimento com a figura de um sujeito neutro, universal, no masculino; 2 . A reflexão crítica sobre a seleção de bens patrimoniais recolhidos para salvaguardar as memórias de mulheres e homens; e 3. A apropriação do conceito de gênero para problematizar a imagem que mulheres e homens constroem do museu e suas experiências nesse espaço. Corroborando com essa proposta, a pesquisadora Silva (2020) em sua dissertação de mestrado sobre a formação docente sobre gênero no museu sinaliza a potência desses espaços para uma educação libertária, pois "o museu não permite uma receptividade passiva [...] provoca pequenas revoluções cotidianas" (SILVA, 2020, p. 161).

O próximo acervo deste artigo apresenta e problematiza três (des)objetos selecionados do Museu de Artes e Ofícios como episódios investigativos. A pesquisa-experimentação com (des)objetos pode ser concebida como registro de afetamentos possíveis e como depoimento das potências que neles residem, ao contrário de tomá-los como objetos sedentários, estagnados e adormecidos.

\section{Terceiro acervo: Composições com (des)objetos no museu}

Um museu pode ser compreendido como um espaço dessacralizado para compreender suas temporalidades, espacialidades e incertezas. É preciso entrar tridimensionalmente no museu (KAZ, 2013), deslocar o olhar e a forma de relacionar com o espaço, resultando em estranhamentos úteis no aprender (ALVES, 2018) e fazendo do museu uma experiência possível e satisfatória. O Museu de Artes e Ofícios, locus investigado, é um espaço cultural que abriga e difunde um acervo museal representativo do universo do trabalho, das artes e dos ofícios no Brasil, promovendo o encontro do/a trabalhador/a com sua história e seu tempo. Criado em 2002, seu acervo conta com cerca de 2,5 mil peças originais dos séculos XVIII ao $\mathrm{XX}$, entre instrumentos, utensílios, ferramentas, máquinas e equipamentos. O Museu se localiza num ponto histórico da cidade de Belo Horizonte, a Praça da Estação, ocupando prédios restaurados das antigas estações das estradas de ferro Central do Brasil e Oeste de Minas.

Entre o final de 2019 e o início de 2020, o pesquisador, desejante de articulações não óbvias entre currículo, museu e gênero, realizou cinco visitas ao museu munido de seu diário de campo e apto à observação participante do cotidiano do museu. As experimentações aconteceram em travessias pelos corredores do museu, escutas seletivas de grupos de visitantes e diálogos profícuos com profissionais do setor educativo. Dois critérios foram utilizados na seleção dos (des)objetos para experimentação - carro de boi, bolsa bruaca e panela de pedra - a diversidade de materialidade, o pertencimento a diferentes ofícios e os ruídos nas visitas, independentemente de períodos históricos ou da ordem de apresentação estipulada pela curadoria do museu.

É importante registrar e agradecer o acolhimento, a disponibilidade e a parceria dos/das profissionais multidisciplinares da equipe do educativo do Museu de Artes e Ofícios na 
investigação que subsidia este artigo. As trocas de ideias, provocações despertadas e o compartilhamento de incômodos e desalinhamentos foram fundamentais na pesquisa, fomentando outros olhares para o aprender no museu, desde o modus operandi do museu até o trabalho educativo com os artefatos culturais do acervo. Olhos e ouvidos atentos, eis o museu!

\section{Primeiro (Des)objeto: Carro de boi}

O primeiro (des)objeto a ser problematizado foi um carro de boi pertencente ao Ofício dos Transportes. Um carro de boi situado numa fazenda é percebido como um meio de transporte de materiais e locomoção de pessoas com valor utilitário agregado para seu/sua proprietário/a. Contudo, o mesmo carro de boi quando deslocado para o acervo do Museu de Artes e Ofícios produz sentidos de outra ordem, da ordem artística, histórica e cultural. A partir desse (des)objeto no museu alguns questionamentos são problematizados em seus atravessamentos de gênero.

Numa conversa entre uma educadora do museu e um grupo de estudantes da Educação de Jovens e Adultos sobre meios de transporte a partir do carro de boi foi possível captar os seguintes diálogos: Respondendo à questão da educadora de quem conduz o carro de boi no transporte de grãos da lavoura, um estudante relatou: "Quando eu morava no interior de Minas [Gerais], minha mãe conduzia o carro de boi carregado de milho para venda do Seu Zé e eu [ainda criança] acompanhava minha mãe no caminho". A educadora retomou dizendo que nem sempre o homem era o condutor, isso dependia da família. Outra estudante questionou: "Mas e a segurança da mulher com uma criança na estrada para não ser roubada ou sofrer outra violência?". A conversa acirrou nesse momento e deu um salto. A educadora ampliou a conversa, utilizando do exemplo do vagão rosa de metrô, destinado exclusivamente para mulheres, para enfrentar a importunação sexual. Outra estudante seguiu com a seguinte ponderação: "Mas e se eu estiver com meu filho adolescente no metrô, eu tenho que me separar dele para entrar no vagão rosa e ele vai sozinho no outro [vagão]? Quem vai protegê-lo?" (DIÁRIO DE CAMPO - ALVES, 2019a).

Parar, observar, soltar a imaginação e experienciar com (des)objetos os ruídos de gênero que os habitam. Como visto, a interpelação nos encontros com (des)objetos, por ser fluida, permite evidenciar uma multiplicidade de conexões no campo curricular. Quando a conversa adquire potência, ela sai do lugar, transborda para outros territórios e invade outras conversas, criando uma rede de articulações impensáveis a priori. O que sinaliza o descontrole sobre essa rede e suas conexões que com sua espontaneidade, como se tivesse vida própria, preenche de possibilidades o currículo-museu. Os deslocamentos provocados no encontro com o (des)objeto carro de boi aponta semelhanças com a criatura impermanente Odradek de Kafka ao criar terrenos movediços no seu entorno que permitem associações e desassociações de ideias no exercício do aprender no e com o museu. A não fixidez de um (des)objeto é uma qualidade útil na arte de compor. 
Vale ressaltar que (des)objetos por si só não são capazes de produzir nenhum desvio de gênero. O "encontro é a palavra-chave" (TADEU, 2002, p.53), apenas no encontro é possível produzir movimentos, afetar e ser afetado pelos (des)objetos e acionar o currículo-museu. Uma questão mobilizadora é: de quê um (des)objeto é capaz? Como estratégia metodológica de dar importância a sua capacidade e não a uma suposta essência. Nos encontros com (des)objetos, o que interessa é "saber quais composições são feitas e quais composições podem ser feitas e se elas são boas ou más do ponto de vista da potência de agir [para, assim,] passar da formação para a composição, do desenvolvimento para a combinação" (TADEU, 2002, p. 53-54). É mister destacar que (des)objetos nunca se esgotam, uma vez que sempre deixam restos, linhas soltas como o Odradek, para as próximas composições nos próximos encontros pelo museu.

Combinar um carro de boi com um vagão rosa, destaque crítico à escolha da cor estereotipada como feminina, do metrô como meios de transporte em interface com gênero é potencializar o currículo-museu ao desliteralizar o objeto e ressignificar a linguagem. Um currículo-museu acontece nessas composições com (des)objetos ao produzir modos de subjetivação inconcebíveis até então. Compor é unir, misturar, compartilhar e produzir outros sentidos, outras leituras e outras possibilidades. As composições com o (des)objeto carro de boi nos levaram para o mundo dos transportes na generificação dos vagões do metrô, o que evidenciou desigualdades e precariedades (BUTLER, 2018) entre corpos na elaboração de políticas públicas de proteção. Cirino e Castro (2019) ao pesquisarem a objetificação do corpo da mulher no transporte público fazem uma crítica às normativas legais, em especial ao Direito Penal com a Lei 13.718/18 de importunação sexual, que ao tentar coibir a violência sexual desconsideram a necessidade de "desreificação da performatividade e a ressignificação das categorias de gênero e sexo" (CIRINO e CASTRO, 2019, p. 428). Para as autoras é preciso trazer a pauta da violência de gênero para o debate público e não apenas ampliar a intervenção punitiva estatal.

Composições com (des)objetos no museu podem produzir modos de subjetivação que buscam "estratégias para desgenerificar, desaprender, subverter performances de gênero" (PARAÍSO, 2019, p. 197). Sendo gênero produzido e praticado por instituições (ALVES, 2020), o museu torna-se um espaço privilegiado nessa tarefa pois, diferentemente da instituição escola, está menos susceptível e vulnerável ao currículo tradicional escolar. Está também menos controlado nos materiais que disponibiliza e nos sentidos que divulga. Por isso, possibilita a elaboração de outros currículos e outras experimentações nos processos de aprendizagem. Museu é lugar de aprender gênero por meio do letramento museal nas interações com (des)objetos. Entrar no museu é ampliar a visão de mundo, pois museu "é lugar para se entrar de corpo inteiro com todos os sentidos despertos e atentos, é onde a cidade (a história) se reconta. Rebrota." (KAZ, 2013, s/p). Um currículo-museu pode ser um lugar para exercitar a resistência aos saberes e poderes (FOUCAULT, 1984) que conformam sujeitos e corpos segundo normas binárias de gênero.

$\mathrm{Na}$ perspectiva do letramento museal, as reflexões oriundas das composições podem promover fraturas no discurso hegemônico e naturalizado de gênero, fazendo circular o conhecimento reflexivo. Pesquisar um currículo-museu com gênero é lidar com a 
transgressão artística, cultural e histórica, rompendo com normas que formatam e engessam objetos do acervo museal numa única leitura, tornando assim o currículo desejante de aprender e de vivenciar. Quando os artefatos do museu foram selecionados pela curadoria para compor o acervo do Museu de Artes e Ofícios, eles não foram pensados como elementos para aprender gênero, mas como um registro patrimonial de um tempo histórico e cultural da sociedade brasileira. Cabe, portanto, ao currículo-museu possibilitar esses deslocamentos, romper com essas barreiras de formatação, produzir modos de subjetivação outros, atribuindo ao (des)objeto carro de boi propriedades outras a fim de aumentar sua voz no espaço e ultrapassar as fronteiras físicas que o delimitam e o encerram.

Um currículo-museu pode multiplicar e ampliar o espectro do aprender em diferentes territórios da cidade, tornando-se desejante, uma vez que o desejo de aprender está nos encontros e nas interações que realizamos no e com o mundo, podendo aumentar ou diminuir a potência de vida, "o desejo [...] depende mais da conexão com algo que nos convém" (PARAÍSO, 2009, p. 289). Interpelar o (des)objeto, como um artefato linguístico, propicia encontros com o inusitado que nos afetam ao transparecer outros sentidos, como artísticos, culturais e políticos, para algo inicialmente tido como trivial. Não devemos subestimar as trivialidades, pois segundo Barros (2014) é fundamental dar "importância ao desimportante" (BARROS, 2014 p. 84). Como mostramos no $1^{\circ}$ acervo desse artigo, a arte e, principalmente, as/os artistas constituem um campo profícuo para compor com os limites entre o formatado e o desformatado, uma vez que a arte libera o objeto de seu valor predestinado e cria novas ontologias para (des)objetos no currículo.

\section{Segundo (Des)objeto: Bolsa bruaca}

O segundo (des)objeto colocado sob escrutínio da pesquisa-experimentação nesse acervo foi a bolsa de viagem, chamada bruaca, usada pelos tropeiros (condutores de tropa, arrieiros ou bruaqueiros, designação dada aos caixeiros viajantes entre as regiões de produção e os centros consumidores no Brasil no século XVII). Sobre ela, é possível fazer inúmeros questionamentos a fim de problematizar as hierarquias de gênero construídas socialmente que delimitam espaços generificados, interditando qualquer fluxo entre ambos. Uma bruaca é feita de restos de couro, sem alça, pouco maleável, grande e pesada. O que antes era um objeto com função de transporte de alimentos, ferramentas e utensílios, ao ser deslocado para o museu como (des)objeto abre-se para composições e associações pela ótica do letramento museal.

Durante uma visita de estudantes adolescentes de uma escola pública ao museu, uma situação chamou atenção. No Ofício dos Comércio, um educador do museu explicava sobre o trabalho dos tropeiros, quando apresentou a bolsa bruaca. Alguns risos e comentários brotaram no grupo estudantil. O educador aproveitou para perguntar: "Alguém conhece o termo bruaca? Como ele é usado normalmente?". Entre murmúrios, foi possível escutar de uma estudante: "Meu pai, quando está muito bravo, sempre chama minha mãe de bruaca". O 
educador utilizou disso para dialogar sobre discriminação de gênero na linguagem (DIÁRIO DE CAMPO - ALVES, 2019b).

No contexto do relato, chamar a esposa de bruaca sinaliza o poder da linguagem para delegar lugares normativos conforme o gênero. No senso comum, bruaca é sinônimo de velha, desleixada, chata e de difícil trato. Assim como a bolsa dos tropeiros é difícil de ser carregada, uma mulher bruaca é difícil de ser tolerada. Como simulacro pejorativo, tanto a bolsa bruaca, quanto a mulher bruaca trazem efeitos negativos por estarem relacionados ao feminino. Cabe aqui questionar retoricamente: quais modos de subjetivação são produzidos por um discurso que reitera comportamentos discriminatórios e desiguais de gênero?

Em outro momento da conversa do educador do museu com o mesmo grupo, ele disse que ser tropeiro era uma profissão masculina desvalorizada socialmente por ser perigosa, rústica, estressante e, muitas vezes, solitária. O homem que trabalhava na cidade tinha outro status, considerando a hierarquização impregnada no binômio cidade/campo. Neste momento, ele é interrompido por uma questão de um estudante: "Professor [era como ele chamava o educador do museu], mas e o feijão-tropeiro que eu adoro, veio daonde?". Em meio a risos, o educador diz ser um prato culinário, hoje celebrado, feito pelos tropeiros com restos de outras comidas, nem sempre de boa qualidade, acrescido de farinha para render e saciar a fome (DIÁRIO DE CAMPO - ALVES, 2019c).

As composições com os tropeiros no encontro com o (des)objeto bolsa bruaca dialoga com Tarsila do Amaral, expoente no Movimento Artístico da Antropofagia, ao revisitar a cultura e a história tipicamente mineiras e brasileiras, ressignificando-as e, com isso, engendrando novas leituras de mundo. A partir desse relato do diário, é possível perceber que as composições operadas no encontro com o (des)objeto bolsa bruaca podem ser compreendidas como uma espécie de bússola que guia possibilidades de aprender por meio de objetos ordinários transvistos em (des)objetos. Como um pretexto para conversa, nos encontros com (des)objetos é possível aprender sobre gênero em um museu, uma vez que o deslocamento das normas e a reflexão sobre o imponderável são ingredientes fundamentais na produção de um currículo-museu.

Butler (2018) propõe pensar gênero como modos de pensar e julgar, determinando performativamente o limite entre o legítimo e o abjeto, pois a "linguagem tem [o poder] de produzir uma nova situação ou de acionar um conjunto de efeitos” (BUTLER, 2018, p. 35). Nesse contexto, o (des)objeto bolsa bruaca transformado num artefato linguístico propicia usos e desusos da língua, sendo usado para refletir sobre as relações de poder que permeiam normas sociais de produção/reiteração de masculinidades e feminilidades.

Em outra visita perante o (des)objeto bolsa bruaca, desta vez com um grupo de docentes, um educador do museu fez a seguinte pergunta: "Quais são as regras sociais para usar uma bolsa de acordo com o gênero?". Rapidamente uma professora responde: "Se é uma bolsa com detalhes, flores, enfeites de metal, alças decoradas e colorida é bolsa de mulher, a bolsa de homem é mais simples, sem enfeites, normalmente de couro" (DIÁRIO DE CAMPO ALVES, 2020b).

Por meio da questão interpelativa do educador, é possível pensar num "protocolo de gênero", ensinado e reiterado em práticas curriculares normativas na escola (ALVES, 2020) 
e no museu, para uso de acessórios da moda. Um protocolo composto por normas repetidas, acríticas e sem reflexão prévia, do que seja um modelo feminino ou masculino de bolsa. Sobre isso, Butler (2018) sinaliza que um importante caminho para a desconstrução de gênero é sempre questionar as regras sociais, invés de tomá-las como algo natural e universal. Caso os modelos de bolsa por gênero sejam trocados, isso imputaria em potencial risco para a masculinidade hegemônica? Atenta ao mercado consumidor, a indústria da moda tem produzido modelos de bolsas, roupas e acessórios agênero (MOREIRA, 2020), de olho numa parcela da população que quer romper com rótulos e padrões sociais. Nessa direção, é possível pensar que (des)objetos considerados agêneros dialogam com o corpo, também agênero, do Abaporu de Tarsila do Amaral ao colapsar o olhar ontologicamente acostumado de gênero. O colapso, ainda que temporário, da norma abre espaço para a produção de outros modos de existência no mundo que questionam o adestramento de sujeitos e corpos pela sociedade disciplinar (FOUCAULT, 1984).

Um dos grandes desafios no campo de estudos de gênero é a quebra do pensamento universalista na determinação de pares opostos - homem/mulher, homossexual/heterossexual transgênero/cisgênero - que permeia o senso comum, em especial, na instituição escola que, muitas vezes, opera por meio da chamada "técnica do apagamento no currículo" (CALDEIRA, 2018, p. 68). Essa técnica faz desaparecer dos currículos e das práticas formativas as temáticas de gênero e sexualidade. Nesse sentido, urge um "currículo como possibilidades" (PARAÍSO, 2018, p. 37) que cria possíveis e conta outras histórias, de outros corpos, em outros territórios. Um currículo que pensa (des)objetos sob outros ângulos e permite aprender sobre e com as diferenças dentro e fora da escola. O encontro com a bolsa bruaca no museu pode nos ensinar como as relações de gênero estão tão implicadas nas práticas sociais que deixam de ser estranhadas e repensadas no currículo.

\section{Terceiro (Des)objeto: Panela de pedra}

O último (des)objeto que integrou a investigação no Museu de Arte e Ofícios foi a panela de pedra, um utensílio clássico da cozinha, em especial, nas cidades do interior de Minas Gerais. A panela de pedra integra o Ofício da Conservação e Transformação dos Alimentos e, como tal, possui múltiplos atravessamentos de gênero.

Durante uma visita mediada de professores/as ao ofício da cozinha, um educador do museu perguntou: “Alguém conhece a música Panela Velha de Sérgio Reis [de 1983] que tem a frase: panela velha é que faz comida boa"? Muitos/as se lembravam e até cantaram versos da música. Entretanto, uma professora comentou com a outra: "Acho essa música muito sexista! Aliás, o que não falta em letra de música brasileira é machismo”. O educador aproveitou dessa oportunidade para colocar em debate música e preconceito: "Alguém conhece outras músicas que também têm conteúdo preconceituoso ou discriminatório?". Um professor respondeu: "As músicas de funk, por exemplo, são muito sexualizadas e preconceituosas, mas meus alunos adoram cantar na sala”. O debate seguiu acirrado com opiniões divergentes (DIÁRIO DE CAMPO - ALVES, 2020a). 
O (des)objeto panela, situado como acervo de um museu de arte e deslocado de sua função como utensílio para cozimento de alimentos, pode produzir composições na problematização de gênero ao promover associações com a estereotipificação do corpo da mulher nas letras de músicas brasileiras. Essas composições preenchem o currículo-museu com gênero, sinalizando alternativas para contestação da naturalização e da essencialização dos modelos universalistas de gênero (ALVES, 2020). Numa referência ao "não-cachimbo" de Magritte, podemos pensar numa "não-panela", isto é, o objeto panela é de tal forma desformatado, decomposto e transvisto como um (des)objeto, que permite com que a imaginação se livre da materialidade que a aprisiona e caminhe livre por outros espaços. Panela como sinônimo de mulher sinaliza a reiteração de estereótipos que podem ser problematizados por meio de diálogos com (des)objetos do museu no intuito de promover fraturas nos discursos discriminatórios de gênero.

Em outro momento de diálogo com educadoras do museu, uma delas me disse:

Certa vez, eu estava com um grupo pequeno de estudantes de Pedagogia de uma faculdade particular e durante a conversa sobre panela, cozinha, lugar do feminino etc, surgiu a discussão do mercado de trabalho para as mulheres e dos preconceitos que elas sofrem" (DIÁRIO DE CAMPO - ALVES, 2020a).

O encontro com o (des)objeto panela propiciou composições com o campo do mercado de trabalho conforme o gênero. Nessa direção, a teoria da divisão sexual do trabalho (SOUSA e GUEDES, 2016) pode ser uma estratégia útil na discussão histórica sobre desigualdades salariais, assédio no trabalho, licenças-maternidade e paternidade e seu impactos na produtividade, bem como a diferenciação de postos de trabalho e promoções de acordo com gênero. As pesquisadoras Sousa e Guedes (2016) sinalizam a importância de analisar a interface entre escolaridade e inserção no mercado de trabalho por gênero, uma vez que nem sempre os melhores cargos em empresas são ocupados pelas pessoas mais escolarizadas.

Ainda no encontro com o (des)objeto panela, outras composições podem ser acrescidas, como a dificuldade que muitas pessoas trans e travestis enfrentam para conseguir trabalho no Brasil. Segundo Almeida e Vasconcellos (2018), "no Brasil o emprego formal não faz parte da vida da população trans [...] estima-se que em torno de $90 \%$ das mulheres travestis e transexuais se prostituam" (ALMEIDA e VASCONCELLOS, 2018, p. 307), o que revela a importância do investimento em políticas públicas de inserção no mercado de trabalho para essa população. Subjetividades trans denunciam a heterogeneidade de elementos que as conformam, fazendo-se e desfazando-se ao tentar escapar dos mecanismos de poder institucionalizados na escola, na saúde e também no mercado de trabalho que capturam a potência de transformação dos corpos (FOUCAULT, 1984).

$\mathrm{O}$ nomadismo que permeia o currículo-museu com gênero aponta para $o$ desmantelamento das oposições binárias de gênero com o objetivo de conectar e de construir alianças necessárias para reinventar a vida. As inquietações instigadas no encontro com (des)objeto podem sinalizar uma concepção de currículo alargada na qual cabem as discussões de estereótipos, preconceitos e discriminações, normalização, resistência, 
equidade e igualdade de direitos. Assim, um currículo-museu, por ser um "artefato hospitaleiro da diferença" (PARAÍSO, 2019, p 163), pode oportunizar a inclusão de dissidentes da norma nas práticas sociais de letramento do e no mundo. Sendo "cheio de possibilidades múltiplas pela matéria diversa que o constitui' (PARAÍSO, 2009, p. 289), um currículo-museu faz contraste ao currículo tradicional escolar por este ser refratário e hermético a qualquer diferença. Ensinar e aprender sobre gênero, incluindo e visibilizando a dissidência, por meio de interações com (des)objetos é a premissa de um currículo-museu que tem primazia pela prática da alteridade em encontros que afetam a potência da vida.

A exemplo do que ocorreu com as interações reflexivas de gênero com o carro de boi e com a bolsa bruaca, as composições com uma, aparentemente simples, panela de pedra do acervo de um museu forneceram elementos instigantes para discutir e problematizar práticas e discursos sexistas, misóginos e transfóbicos arraigados num modelo de sociedade hierarquicamente organizada e pautada na desigualdade de gênero.

\section{Quarto acervo: Efeitos de um currículo-museu}

Efeitos dos encontros com arte! Efeitos das composições com (des)objetos no museu! Efeitos de um currículo-museu com gênero! O último acervo do artigo propõe, ainda que brevemente, apontar efeitos e redes de conexões, sinalizando rotas na experimentação de um currículo-museu a partir da imersão no Museu de Artes e Oficios.

Não existe roteiro, nem manual para as práticas de composição e interpelação sobre as relações de gênero nos encontros com (des)objetos. Porém, seguimos os conselhos perspicazes do poeta Barros (2014) para fugir da linha reta e acostumada, brincar com as palavras, perseguir a desformatação do mundo, desnaturalizar o olhar, perturbar o sentido normal das ideias e reinventar a vida. Para colocarmos um currículo-museu em ação devemos atentar à desconstrução do pensamento formatado e fomentar a imaginação andarilha durante a imersão de corpo inteiro no museu. Aberto às composições que brotam, aos ruídos de gênero que eclodem e às combinações que se estabelecem temporariamente com (des)objetos. Desfazer o protagonismo, o essencialismo e o idealismo em prol da horizontalidade e da imanência numa rede de conexões em práticas curriculares. Fazer transbordar um currículo em múltiplas direções!

No currículo-museu com gênero, a arte do encontro e da composição (TADEU, 2002) com (des)objetos consiste numa estratégia metodológica importante para promover práticas sociais de leitura de mundo no museu, o chamado letramento museal (ALVES e SOUZA, 2017). Pois, a partir da interpelação com (des)objetos do museu podemos questionar algumas relações de gênero que os atravessam e os compõem e que nem sempre são perceptíveis ou mensuráveis. Nessa direção, a bricolagem de campos do saber (PARAÍSO, 2019) como a museologia social, o multiletramento - em especial o letramento museal - e os estudos póscríticos de currículo e gênero podem estimular o aprender crítico e reflexivo fora do território formal da escola, bem como a produção de conhecimentos multidisciplinares. 
Partimos da concepção de museu como um espaço dessacralizado aberto ao multiletramento, isto é, às múltiplas leituras de mundo e, portanto, propício às práticas de ensinar e de aprender. Pela ótica do letramento museal podemos sintetizar algumas características importantes na experimentação de um currículo-museu: 1. Provoca sinestesia nos processos interativos, afinal é preciso estar com os sentidos despertos (visão, audição, tato, audição e mesmo o paladar, ainda que na memória, como a lembrança de gosto de feijão feito na panela de pedra da casa da minha avó) para a experimentação; 2. É acronológica, pois a ordem das interações com (des)objetos em um museu é arbitrária, um currículo com múltiplas entradas e saídas (PARAÍSO, 2018), podendo começar do final do acervo e terminar no início do acervo sem preocupar com a cronologia dos períodos históricos, temporais ou geográficos das peças; e 3. Não é escolarizada, pois a proposta não é transpor o modus operandi da escola para o museu, mas construir lógicas próprias de letramento e do aprender com gênero nos encontros com (des)objetos em um museu, rompendo com o aprisionamento escolarizado da cultura e da arte.

Nos acervos que compõem esse artigo, partimos do universo das artes plásticas e da literatura de René Magritte, Franz Kafka e Tarsila do Amaral para ensaiar uma definição de (des)objeto, o que não é tarefa fácil, uma vez que (des)objetos sempre deixam algo escapar, como restos que evidenciam sua incompletude. Nesse ensaio, fizemos um exercício de tomar emprestadas algumas dimensões desses/as artistas e de suas obras como o nomadismo, a incerteza, a incompletude e a impermanência. Assim, podemos dizer que (des)objetos criticam a vinculação da arte às coisas, à materialidade, dando foco ao processo de interpelação como constitutivo do próprio (des)objeto que se expande, contamina o entorno e torna o museu, em si, parte dele.

(Des)objetos deslocam certezas e indagam quem se põe diante deles, fazendo-se outros no momento mesmo da relação com a pessoa que visita o museu. Cada um dos (des)objetos problematizados nesse texto possui uma intrincada rede de conexão de sentidos que os perpassam, cabendo-nos a incumbência de evidenciá-los no currículo. Um meio de transporte rural como o carro de boi, um objeto utilitário do cotidiano como a bolsa bruaca e um utensilio de cozinha como a panela de pedra, por si só, apenas reiteram usos, nomenclaturas e comportamentos cristalizados socialmente. Contudo, quando tais objetos do museu são desestabilizados, recompostos e transvistos, tornam-se (des)objetos e, como tal, são inconstantes, estando entre lugares na produção de subjetividades em um currículo-museu.

Pela perspectiva dos encontros interativos e interpelativos, os artefatos culturais de um currículo-museu atuaram como pretexto para interrogar posições de sujeito no mundo. Ao longo dos acervos desse artigo, indagamos sobre as subjetividades produzidas a partir do exercício discursivo de estranhamento de (des)objetos museais, sobre os modelos de feminilidades e masculinidades reiterados ou interditados por esses discursos e sobre os escapes e vazamentos de gênero que passam despercebidos nas relações com (des)objetos de um museu.

Por fim, retomando o subtítulo do artigo - experimentações para produção de (des)objetos museais - foi possível evidenciar a pluralidade das práticas do aprender no território de um currículo-museu. As composições (des)objetificadas no museu corroboraram 
para desnaturalizar essencialismos, criando momentos de estranhamento do ordinário e de acolhimento da pluralidade (ALVES, 2018). Momentos como combustível para o exercício do aprender, um aprender desejante de invenções, contraposições, insubordinações e extrapolações, assim como um desenho - de um carro de boi, de uma bolsa ou de uma panela - que em sua intensidade vital rompe os limites da folha de papel, quebra a ponta do lápis, se reinventa e peregrina por outros territórios possíveis.

\section{Referências}

ALMEIDA, Cecília Barreto e VASCONCELLOS, Victor Augusto. Transexuais: transpondo barreiras no mercado de São Paulo? In: Revista Direito G. V. Escola de Direito de São Paulo da Fundação Getúlio Vargas, v. 14, n. 2, p.302-333, maio-ago, 2018.

ALVES, Cláudio Eduardo Resende e SOUZA, Magner Miranda. Educação para as relações de gênero: eventos de letramento na escola. Curitiba: CRV, 2017.

ALVES, Cláudio Eduardo Resende. Gênero e educação nos museus: práticas de letramento. In: SILVA, Fernanda et al. (Orgs.). Diálogos da formação docente com diferentes sujeitos e espaços educativos. Curitiba: CRV, p. 357-374, 2018.

Políticas públicas, gênero e currículo: notas para equidade. In: Revista Educação em Questão. Universidade Federal do Rio Grande do Norte, 58(58), out/dez., p.1-23, 2020.

. Diário de campo. Belo Horizonte: 16 de outubro de 2019a

Diário de campo. Belo Horizonte: 23 de novembro de $2019 \mathrm{~b}$

Diário de campo. Belo Horizonte: 04 de dezembro de 2019c.

Diário de campo. Belo Horizonte: 23 de janeiro de 2020a.

Diário de campo. Belo Horizonte: 08 de fevereiro de 2020 b.

BARROS, Manoel de. Meu quintal é maior do que o mundo. Rio de Janeiro: Objetiva, 2014.

BUTLER, Judith. Corpos em aliança e a política das ruas: notas para uma teoria performativa de assembleia. Rio de Janeiro: Ed. Civilização Brasileira, 2018.

CARVALHO, Vânia Carneiro. Cultura material, espaço doméstico e musealização. In: Varia História. Faculdade de Filosofia e Ciências Humanas. Universidade Federal de Minas Gerais. Belo Horizonte, vol. 27, no 46, p. 443-469, jul/dez, 2011.

CALDEIRA, Maria Carolina Silva. Relações de gênero no currículo da formação de professoras para a alfabetização: uma análise do Pacto Nacional pela Alfabetização na Idade Certa - PNAIC. In: PARAÍSO, Marlucy Alves e CALDEIRA, Maria Carolina Silva. (Orgs.) Pesquisas sobre currículos, gêneros e sexualidade. Belo Horizonte: Mazza Edições, 2018, p. 53-72.

CIRINO, Samia Moda e CASTRO, Bruna de Azevedo. O corpo-objeto da mulher: reificação da lógica opressora das relações de gênero no crime de importunação sexual. In: Argumenta Journal Law, n. 30, p. 405-433, jan/jun, 2019.

DELEUZE, Gilles. Nietzsche e a filosofia. São Paulo: N-1 Edições, 2018.

DELEUZE, Gilles e GUATTARI, Félix. Mil Platôs. Vol. 4. São Paulo: Editora 34, 2012.

DERRIDA, Jacques. Gramatologia. Tradução de Mirian Chnaiderman e Renato Ribeiro, São Paulo: Perspectiva, 2006.

FOUCAULT, Michel. História da sexualidade: o uso dos prazeres. Vol. 2. Rio de Janeiro: Graal. 1984. 
Isto não é um cachimbo. Rio de Janeiro: Paz e Terra, 1988.

IZABEL, Tomaz Amorim. Quimera incapturável. Pandaemonium, São Paulo, v. 19, n. 28, set.-out., p. 74-100, 2016.

KAZ, Leonel. O que o museu tem a ver com a educação? 2013. Disponível em: http://goo.gl/0y1Tc3 Acesso de 13 de junho de 2020 .

MOREIRA, Tatiana Lourenço. Moda agênero: ativismo e consumo na indústria cultural contemporânea. 2020.130f. Dissertação (Mestrado). Universidade Federal do Ceará. Programa de Pós-graduação em Psicologia, Fortaleza, 2020.

MOUTINHO, Mário Caneva de Magalhães. Definição evolutiva da sociomuseologia: proposta de reflexão. In: Cadernos de Sociomuseologia. Lisboa: Universidade Lusófona de Humanidades e Tecnologias n. ${ }^{\circ} 28$ p. 39/44, 2007.

NEW LONDON GROUP. A pedagogy of multiliteracies: designing social futures. In: CAZDEN, COURTNEY, FAIRCLOUGH. NORMAN et al. Harvard Educational Review. Spring, 1996.

PAQUET, Marcel. Magritte. Lisboa: Paisagem, 2006.

PARAÍSO, Marlucy Alves. Currículo, desejo e experiência. In: Revista Educação e Realidade. 34(2), p.277293, mai/ago, 2009.

mai/ago, 2010.

. Diferença no currículo. In: Cadernos de Pesquisa, v.40, n.140, p. 587-604,

. Currículo nômade: quando os devires fazem a diferença proliferar. In: KIRCHOF, Edgar Roberto; WORTMANN, Maria Lúcia e COSTA, Marisa Voraber. (Org.). Estudos Culturais e Educação: Contingências, articulações, aventuras, dispersões.1ed. v. 1. Canoas: Editora da ULBRA, p. 269 $288,2015$.

. Uma vida de professora que forma professores/as e trabalha para o alargamento do possível no currículo. Curitiba: Brazil Publishing, 2019.

PARAÍSO, Marlucy Alves e CALDEIRA, Maria Carloina Silva. (Orgs.) Pesquisas sobre currículos, gêneros e sexualidade. Belo Horizonte: Mazza Edições, p. 23-52, 2018.

RECHENA, Aida. Museologia social e de gênero. In: Cadernos do CEOM , ano 27, n. 41, 2014.

SILVA, Daiana Maria. "Percurso Museológico História de Mulheres vozes e silêncios": olhares sobre a experiência numa formação de professores/as da Secretaria Municipal de Educação de Belo Horizonte. Dissertação (Mestrado). 171 p. Programa de Pós-Graduação em Educação Tecnológica: CEFET - MG, 2020.

SOUSA, Luana Passos e GUEDES, Dyeggo Rocha. A desigual divisão sexual do trabalho: um olhar sobre a última década. In: Estudos Avançados. Universidade de São Paulo. 30 (87), 2016.

TADEU, Tomaz. A arte do encontro e da composição: Spinoza + Currículo + Deleuze. In: Educação e Realidade. Universidade Federal do Rio Grande do Sul. 27(2):47-57 jul/dez, 2002.

VAQUINHAS, Irene. Museus do feminino, museologia de gênero e o contributo da história. In: Museu e Estudos Interdisciplinares. [on line] 3, p.1-15, 2014. 


\section{Correspondência}

Cláudio Eduardo Resende Alves: Pós-Doutor em Educação pela UFMG e Doutor em Psicologia pela PUC Minas. Integrante do GECC - Grupo de Estudos e Pesquisas em Currículos e Culturas/UFMG. Gestor de Políticas Públicas Educacionais da SMED - Secretaria Municipal de Educação de Belo Horizonte/MG. Gerente do Núcleo de Educação, Cultura e Cidadania da Diretoria da Educação Inclusiva e Diversidade da SMED/BH.

E-mail: cadupbh@gmail.com

Marlucy Alves Paraíso: Professora Titular da Faculdade de Educação e do Programa de Pós-Graduação da UFMG. Pesquisadora 1C do CNPq e Vice-presidente da ABdC: Associação Brasileira de Currículo. Supervisora do Pós-Doutorado. Coordenadora do GECC - Grupo de Estudos e Pesquisas em Currículos e Culturas/UFMG.

E-mail: marlucyparaiso@gmail.com

Texto publicado em Currículo sem Fronteiras com autorização dos autores. 